\title{
BP case study: KM team structuration and sense-making (Part I)
}

\author{
C. Gorelick \& K.A. April* \\ Graduate School of Business, University of Cape Town, \\ Private Bag, Rondebosch 7701, Republic of South Africa \\ aprilkur@gsb.uct.ac.za
}

Received October 2003

\begin{abstract}
Recently, an increasing amount of research and literature has focused on knowledge management, organizational learning and virtual teams. Building on Parsons 1950s and 1960s work around general Theory of Actions, this paper uses Schwandt's $(1994 ; 1995 ; 1999)$ dynamic organizational learning model that considers both cognition and action, as a framework, to explore the factors that a virtual project team (the British Petroleum Knowledge Management Team) used to contribute to a multi-national's learning, along two-dimensions: structural and sense-making dimensions.
\end{abstract}

\begin{abstract}
Despite a growing body of literature in both organizational learning and groupware research, there are few studies on the relationship between the two areas. Exceptions are the empirical study of a groupware implementation by Riggs, Bellinger and Krieger (1996) and Neilson's (1997) case study exploring the influence of a collaborative technology - this three year case study on BP's virtual team provides new, qualitative insights into previously unexplored areas of research in the knowledge management discipline.
\end{abstract}

*To whom all correspondence should be addressed.

\section{Introduction}

In recent years, an increasing amount of research and literature has focused on concepts such as the 'knowledgebased economy' (Drucker, 1993; Prusak, 1997; Botkin, 1999), 'organizational learning' (Senge, 1990; Popper \& Lipshitz, 1998), 'virtual teams' (Lipnack \& Stamps, 1997; Townsend, DeMarie, \& Hendrickson, 1998; Duarte \& Snyder, 1999) and 'computer-supported collaborative work' (groupware or collaborative technology; Orlikowski, 1992; Orlikowski \& Yates, 1994; Schrage, 1995; Lloyd \& Boyle, 1998). Yet, much of our understanding of organizational learning is not based on empirical field research. After nearly 30 years, the research, in large part, remains murky, confused, and difficult to penetrate (Garvin, 1993).

In the field, organizations are focusing on teams as a means to deliver results in a knowledge-based economy. Project teams have varied communication, coordination, and information needs. These teams are often virtual, working from physically dispersed offices, working from home, or traveling, creating new logistical problems. Companies increasingly rely on communications and information technology (IT) to support their globally-linked knowledge workers. At the same time, the continuing pace of change and competition have sparked significant interest in the way organizations process, distribute, and store information, as well as how they create new knowledge and learn.

To ensure that knowledge, created by teams, is transferred to the organization for use in future projects, organizations are establishing large-scale knowledge management functions and initiatives. Technology, in the form of collaborative technology, is a major mediator for the communication, coordination and information sharing actions involved in these initiatives. To remain competitive today, firms must leverage individual expertise related to industries and functional specialties between organizational units and across multiple locations to meet customer needs quickly. Despite a growing body of literature in both organizational learning and groupware research, there are few studies on the relationship between the two areas. Exceptions are the empirical study of a groupware implementation by Riggs, Bellinger and Krieger (1996) and Neilson's (1997) case study exploring the influence of a collaborative technology - LotusNotes ${ }^{\circledR}$ - on organizational learning. Extending knowledge of how teams contribute to organizational learning, and the role of collaborative technology, have potential to both improve knowledge management initiatives and increase the return on investments in collaborative technology.

To provide context for this research study, the following definitions were used:

1. Collaborative technologies: A subset of groupware, collaborative technologies provide sets of tools that support two or more people engaged in achieving common objectives [using communication and information sharing technology] (Martin, 1994).

2. Computer-supported cooperative work: Research area that studies the use of computing and communication technologies to support group and organizational activity (Olson \& Olson, in press). 
3. Groupware ${ }^{1}$ : Networked computer software and hardware that enables synchronous and asynchronous collaboration for increased productivity (Engelbart, 1992).

4. Knowledge management: A process that systematically makes use of the knowledge in the organization through tools and techniques that applies the knowledge to business problems. The process enables a collective group to capture, share, and use available knowledge, lessons and practices to deliver business results.

5. Organizational learning: The process that enables an organization to transform information into valued knowledge which, in turn, increases the organization's long-term adaptive capacity (Schwandt, 1999).

6. Sense-making: Literally, the making of sense (Weick, 1995). An interpretive process that is necessary for organizational members to understand and to share understanding about features of the organization, e.g., what it is about, what it does well and poorly, the problems it faces, and how they should be resolved (Feldman, 1989).

7. Structuring: A dynamic integration of organizational structures, roles, norms, objects and processes (Schwandt, 1999).

8. Virtual team: A team that has members dispersed across distance and time, who are linked together by some form of electronic communication technology, and who are only able to physically interact as a team on a limited (infrequent) basis (Sessa, Hansen, Prestridge \& Kossler, 1999).

\section{The problem}

The primary problem that drove this investigation was the need to understand the factors that contribute to organizational learning. Major efforts to integrate structural factors (e.g., information technology, norms, roles, leadership) and group or team process factors (e.g., mission, objectives, goals and values) to support knowledge management and organizational learning have led to newly created positions with titles such as chief learning officer, chief knowledge officer and director of knowledge management. It is assumed that technology is a key requirement for virtual teams (Opper \& Fersko-Weiss, 1992; Lipnack \& Stamps, 1997; Duarte \& Snyder, 1999). The importance of studying the use of collaborative technology from the social and group perspective is well-supported (Morosini, 2000; Darr \& Goodman, 2000; DeSanctis \& Poole, 1994; Johnson-Lenz \& Johnson-Lenz, 1994; O’HaraDevereaux \& Johansen, 1994; Orlikowski, 1992; Rheingold, 1993; Schrage, 1995). Thus the secondary problem the study addressed was how collaborative technology contributed to organizational learning during a virtual team's project.

\section{Purpose of the study}

The three-year case study was designed to learn how a virtual project team contributed to organization-wide learning, with specific interest in two dimensions: structuring and sense-making. The structural dimension of organizational learning focuses on specific mechanisms information technology, roles, norms, leadership, rewards and recognition, education and development - that contribute to a team's learning and performance. The sensemaking dimension of organizational learning focuses on shared values, language, schema, and scripts. The study interpreted how the team continually processed, interpreted, and acted on new information, thus creating new knowledge in the process of meeting team goals. The team goals, to actively contribute to knowledge management, made this study an optimum case.

\section{Research questions}

The major research question for the study was: In what ways, if any, did the virtual knowledge management project team contribute to organizational learning? A key supporting question was: In what ways, if any, does collaborative technology play a role?

Subquestions considered the following:

What structuring variables were evident in the virtual knowledge management team and how did they contribute to organizational learning, both within the virtual team and at the organizational level?

What sense-making variables were evident in the virtual knowledge management team and how did they contribute to organizational learning, both within the virtual team and at the organizational level?

\section{Research methodology}

The lack of prior theoretical and empirical research on this topic necessitated 'going to the field', and conducting a longitudinal case study. Consequently, the general approach of this study is naturalistic in character. As with most case studies, multiple data-collection methods were used interviews, observation, and review of documents and electronic databases to create rich descriptions.

This study sought to describe, as its unit of analysis, how the individuals of the virtual project team worked together and contributed to organizational learning at the team and corporate levels. The case study was based on a framework (Figure 1) that provided an overall structure for the study (Miles \& Huberman, 1994). This framework guided the order in which the study was conducted, linking the construct of organizational learning in a virtual project team with the goals of producing thick descriptions to add to the understanding of the OLSM. 


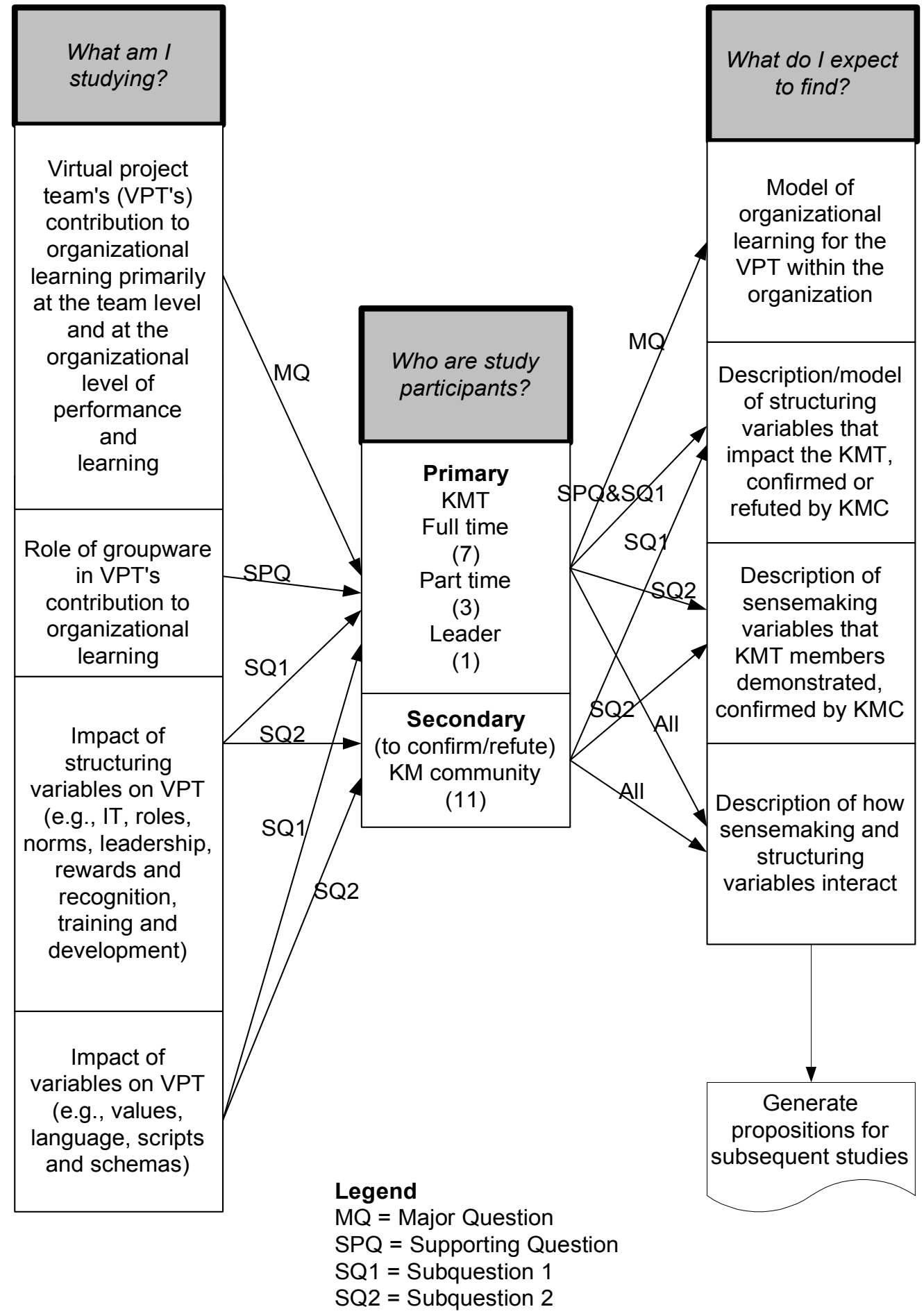

Figure 1: Study framework

The 14-month research fieldwork was primarily based on semi-structured individual interviews. Initially, preliminary mapping was designed for background and context information, as well as to familiarize the data researcher (only Dr. Gorelick conducted data collection) with the structure, language, and history of both BP and the KMT (knowledge management team), and familiarize the team and KMC members (knowledge management community of practice) with the data researcher. Activities included observation at meetings, phone conversations, e-mail communications, internal and external documents review, and review of the BP Intranet. In addition to the KMT members, the study included informants from the broader 160-person KMC. The complete list of respondents evolved through the study using the snowballing technique (Yin, 1989; Patton, 1990).

There are no rules to determine population size in qualitative research so defining 'adequate' is subjective. Seidman (1991: 61) suggests two independent tests for deciding an acceptable number of participants: (1) sufficiency test, to ensure that a variety and range of participants adequately describe the population being studied, and (2) theoretical saturation, the point in the research process where "no 
additional data are being found'. The following serve as evidence for having reached theoretical saturation: (a) data being collected are redundant and thereby not providing any new or useful information, (b) the information categories have been developed sufficiently to validate all relevant elements, including their variations and processes, and (c) the associations between the categories of information are substantiated (Strauss \& Corbin, 1990: 188). The standard applied in this study for the KMC was theoretical saturation.

The researchers developed a list of coding categories expected to contribute to organizational learning based on the literature review, which became the repositories for the first phase of data analysis. The preliminary coding scheme was laid out as follows:

1. Technical infrastructure - hardware, software and communication technology that allows anyone, within the organization, to communicate and exchange information from anywhere, at anytime.

2. Application flexibility - the ability to customize software to meet individual team requirements without a long development cycle, e.g., create an interview form that is project-specific.

3. Shared context - a clear common understanding of mission, objectives and goals, allowing team members to work 'on the same page'.

4. Norms - agreed-upon rules, processes and procedures that all team members follow, e.g., we will always write and file meeting note summaries.

5. Leadership - characteristics or functions that inhibit or encourage a virtual team's success, e.g., active user of team tools, processes and procedures.

6. Roles - formal or informal actions assumed by team members, e.g., knowledge manager.

7. Rewards - extrinsic or intrinsic rewards that inhibit or encourage a virtual team's success, e.g., bonuses.

Prior to field interviews, a pilot interview was conducted to check the interview questions for clarity, content, and completeness (Yin, 1994). Following the pilot interview, a detailed analysis of the interview questions and process was conducted. Feedback validated the substance of the questions. Minor changes were made to clarify questions and to allow for more open-ended conversation.

As this was a discovery-oriented investigation, data collection for this study consisted primarily of systematic, semi-structured, open-ended interviews (Yin, 1989). Additionally, a large volume of data from other sources such as observation, Websites, articles, documents, speeches, informal communications (email and phone) and video clips were collected.

Individual interviews served three purposes in this study. First, they were used to answer the research questions related to the structuring media of exchange. Second, they provided insight into collective values, language, schemas and scripts for shared understanding (sense-making) within the team. Finally, the KMC interviews corroborated or refuted the perceptions of the KMT members and reduced the potential of reporting researcher-biased findings. This was a form of triangulation, a method of ensuring trustworthiness in the research.

To serve the above purposes, a 'general interview guide approach' (Patton, 1990: 280) was used to gather general information, and 'structured open-response questions' were used to obtain answers to the research questions. The written protocol ensured that topics predetermined as relevant to the study were not overlooked (Patton, 1990: 282) while the researcher was able to maintain a conversational spontaneous style necessary for discoveryoriented investigations.

The advantage of obtaining 'thick description' of each informant's perspective on relevant factors, meanings, and events surrounding their experiences was intended to capture potential omissions and justified using the interview guide for this study.

The interview protocol had three sections: (1) reminded the participant of the purpose of the study, (2) was designed to gain from the informant 'a verbal description of significant features of the cultural scene' - participant's interpretation of the KMT's mission, goals, roles, use of technology, norms, and leadership, as well as roles played by team members. This section gathered explicit information about structuring and sense-making focusing on the factors identified in the conceptual framework. Section 3 explored knowledge management and virtual project team concepts in order to understand the KMT approach in a broader context and add information for the sense-making analysis. An example of a question designed to elicit perceptions of concepts and approaches is: If you were in a new job and had to design a knowledge management system what would you do? Issues might include but are not limited to processes, procedures, and technology.

In total $11 \mathrm{KMT}$ members and $10 \mathrm{KMC}$ members were formally interviewed (1-2 hours on average) by the data researcher, always one-on-one, sometimes by PC video conferencing at their office or home. A few days prior to each scheduled interview the researcher e-mailed (which included interview questions) the informant duplicate consent and background forms if completed copies had not yet been received. Each participant was asked for permission to audio-tape the interview (none objected), and following each interview, the audiotapes were duplicated and given to a professional transcription company for verbatim narrative transcription. After being validated against the source audiotape, each participant received an electronic copy of his or her transcript for review and revision, which served as members check on the validity of the data (Lincoln \& Guba, 1985) - only two participants noted corrections.

In addition to the interviews, the data researcher observed a number of group gatherings. 
1. KMT Away Days were significant research events at the beginning and conclusion of the fieldwork.

2. A celebration for the KMT and selected friends of the team.

\section{Video and audio conferences of the Retrospect process.}

4. A meeting with business unit members of the KMC was observed in the USA.

Summaries of the above were entered into a Lotus Notes database. All field notes were reviewed for purposes of triangulation and to help identify topics for further research in individual and group interviews.

Documentary evidence for this study was abundant, both in electronic and paper form. The data researcher had access to the BP Intranet, the KMT electronic 'shared folders', used as a living repository for all team documents including actions, team management, events, objectives, technology, knowledge management strategy, meeting minutes, presentations, etc. The site also included significant video clips taken at events, expert presentations, and contributions from BP employees for Knowledge Assets. Several other electronic sources were made available to the data researcher. CDs were reviewed, and digital copies of road maps for the KMT were also reviewed. Printed documents included official publications (e.g., annual reports), internal publications (e.g., Technology Review), newspaper articles and brochures created and distributed by the KMT about their offerings. Documents were a source for triangulation. Data collected during interviews and from observation were checked against documentary evidence (printed and electronic) and vice versa, thus enhancing the credibility of findings (Lincoln \& Guba, 1985).

This study used the most common methods qualitative researchers employ: observation, interviewing, researcherdesigned instruments, and content analysis of human and electronic artifacts for data collection (LeCompte, Preissle $\&$ Tesch, 1993: 158). The four classic qualitative analysis (Miles \& Huberman, 1994: 10) components were:

(1) data reduction - contact sheet used to summarize each interview, and the subsequent coding of these forms to find patterns, through a multiple coding/analysis methodology (KMT first, then a modified version for the $\mathrm{KMC)}$ :

- $\quad$ reading of each transcript

- a preliminary analysis which summarized the highlights of each interview on a contact summary sheet (inductive consistency)

- develop an initial coding scheme

- $\quad$ all KMT transcripts were then analysed, by annotating the paper interview transcript margins with handwritten codes
- $\quad$ sections of the electronic transcripts were transferred, based on the handwritten codes, to a Word document. The result of this process was a document containing significant quotes organized by the initial coding scheme;

(2) data display - demographic tables and principle descriptor tables were used;

(3) conclusion drawing - processes of noting regularities, patterns, explanations, possible configurations, causal flows, and propositions through constructing a list of quotes by specific descriptors (codes) and a matrix organized by (a) individual; (b) the KMT (group); (c) the business project (group); and (d) BP (the organization). The products of this examination of the data were (a) descriptors by unit of analysis (b) principal descriptors and (c) patterns or dominant themes. These products produced a preliminary finding document using the Schwandt OLSM framework.

(4) verification - testing the validity of conclusions as they developed throughout the study. The products mentioned above were reviewed with outsiders prior to a review with the KMT leader and self-selected members of the KMT. Suggestions were incorporated into the findings presentation and reviewed with additional self-selected members of the KMT and KMC.

\section{Conceptual framework}

This study used Schwandt's (1994; 1995; 1999) dynamic organizational learning model as a framework. Schwandt's model has previously been used to analyze dynamic actions related to organizational learning in a field setting (Casey, 1997; Johnson \& Gorman, 1999; Hinds, 1995).

\section{The dynamic organizational learning model}

This study specifically focused on the learning and performance elements of the General Theory of Action (Parsons, 1968) that are viewed in the Schwandt model as necessary requirements for long-run adaptive capacity. The Organizational Learning Systems Model (OLSM) (Schwandt 1994; 1997 ; 1999) represents an effort to describe the organization as a dynamic knowledge-creating system and, for the purposes of analysis, to operationalize a model that addresses the complex nature of organizational learning. Schwandt posits that organizations are social systems that change as a result of both performance and learning. Schwandt's grounding in Talcott Parsons' (1951) Social Action Theory calls on Parsons' identification of four, integrated elements to social action.

1. Actor/subject: an individual, group or collective.

2. Situation: the physical and social objects to which the actor relates.

3. Symbols: the means through which the actor relates to different situations and assigns meaning to them. 
4. Rules, norms and values: the guiding factors for the actor's relations with the social and non-social objects in his/her environment (Rocher, 1979).

The foundation - Parsons' general theory of social action

Parsons defined four functions (Figure 1) that are a system of dynamic patterns of human acts:

(1) adaptation to the external environment;

(2) goal attainment;

(3) integration of all parts of the organization; and

(4) pattern maintenance to reinforce prevalent behaviours and the organization's cultural patterns.

\section{Purpose}

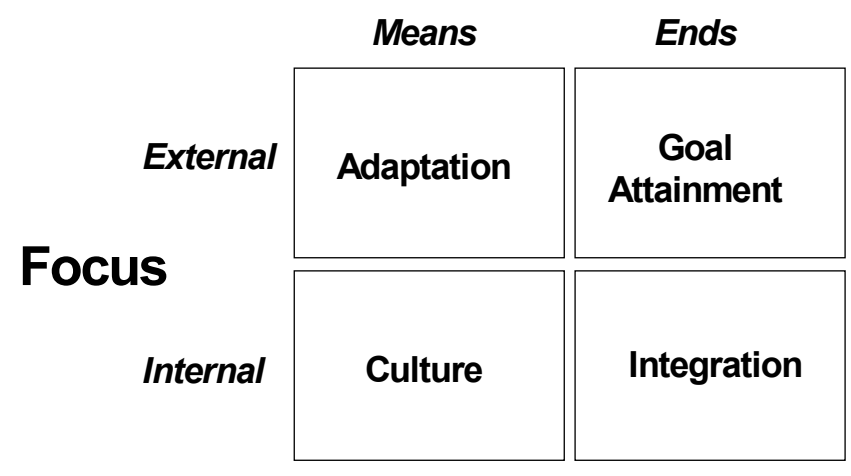

Figure 2: Parsons' four functions

These four functions can be generalized to all levels of analysis (individual, group, organization, and society). The theory addresses how human systems integrate psychological, social and cultural elements of organizational dynamics. Parsons addressed actions from three perspectives: actions associated only with performance, actions associated only with learning, and actions associated with both learning and performance simultaneously. For analysis purposes, Schwandt, Casey, and Gorman (1998) assume that the actions can be separated into two independent subsystems: performance and learning. Although Parsons (1968) postulated that social systems change through both performance and learning actions, his work with learning was limited compared with his work on other aspects of the action theory. Parsons (1968) postulated that information, internalized into knowledge, changes the conditions of the actions, as well as the actions themselves (structuration). The Schwandt model addresses a need to expand on Parsons' work on the learning subsystem, which is described below.
Schwandt's adaptation - emphasizing the learning subsystem

Schwandt (1994) views organizational behaviour as more than performance. He sees the creative capacity that influences the collective's cultural values and uses this view to describe how an organization learns as a system. His model emphasizes the learning aspect of change in Parsons General Theory of Social Action, and emphasizes the relationships and integration of the subsystems, which allows the organization to increase its learning capacity (Gundlach, 1994).

The four functions of Schwandt's learning system (Figure 2) and the Parsons (1968) equivalents are as follows:

1. The Environmental Interface Subsystem (adaptation), which is the locus of information intake and output and requires mechanisms to secure, filter, and expel information.

2. The Action-Reflection Subsystem (goal attainment), which creates valued knowledge from new information, the goal of the learning system.

3. Dissemination/Diffusion or Structuration ${ }^{2}$ Subsystem (integration), which transfers information and knowledge within the organization, thus integrating the learning system. Dissemination techniques are formal procedures and policies that are purposefully directed. Diffusion techniques are informal communication, rumours, and formal communication. Electronic mechanisms are central to this subsystem for virtual teams.

4. The Meaning and Memory Subsystem (culture or pattern maintenance), which maintains mechanisms that establish criteria for judgement, selection, focus, and control of the organizational learning system. Beliefs, values, assumptions, and artifacts - the cultural components of the organization - are included in this subsystem.

\section{Purpose}

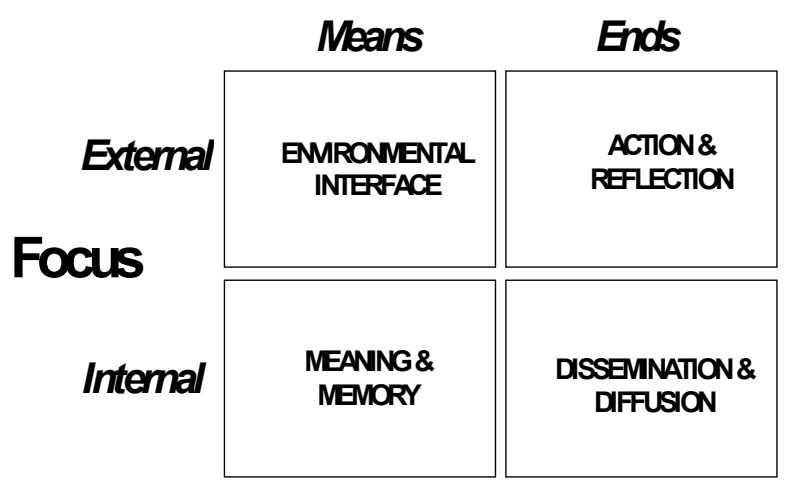

Figure 3: Schwandt's learning subsystems

2 Early versions of the model identified the subsystem as 'Dissemination/Diffusion'. Later versions label this subsystem 'Structuration'. In the figures the earlier name is retained. 
Schwandt's four learning subsystems are interdependent. The arrows in Figure 3 show the relationship between the products of the subsystems. These interchange mechanisms are the elements of input and output that Parsons (1968) defined as a medium of interchange / exchange. The interchange mechanisms are processes, procedures, and roles manipulated by the collective and individual actors who produce invisible networks. They are patterns of action that allow for mutual exchange among the subsystems. The media of interchange / exchange are as follows:

1. New Information, output of the Environmental Interface Subsystem. The learning system accesses new information from the external environment and from within. The subsystem's function is adaptation. New information comes into the system from outside, and leaves the organizational learning system through the adaptation function.

2. Goal-Referenced Knowledge, output of the ActionReflection Subsystem. The goals of the learning system are to adapt through learning. This is different from the goal of the performance system, which adapts through performance. Both contribute to the organization's ability to change for survival. For analysis purposes, the two subsystems are separated.

3. Structuring, an output of the Dissemination-Diffusion subsystem. The integration of organizational structures, information technology, roles, policies, procedures, and processes produces a dynamic result- structuration. The structuring media of exchange integrates the other three subsystems in the organizational learning system. Structuring mechanisms allow for information and knowledge to move within the learning system and the organization.

4. Sense-making, an output of the Meaning and Memory Subsystem. Sense-making functions to accomplish pattern maintenance. The sense-making produced and transferred from the Meaning and Memory Subsystem is represented by language and symbols. This medium makes sense of actions through reflection, moves and classifies goal-referenced knowledge into stored memory, and is required by the DisseminationDiffusion Subsystem to generate appropriate structuring. Language and symbols-defined as words, signals, and knowledge structures (schema and scripts) - are the means that the Meaning and Memory Subsystem uses to communicate with other subsystems. Language and symbols are required to produce useful explicit information, goal-referenced knowledge and the structure for organizational learning (Schwandt et al., 1998).

These four interchange media can be measured via organizational variables such as industry conferences (new information), strategy formation processes (goal-referenced knowledge), roles and norms (structuration), and schema/scripts (sense-making).

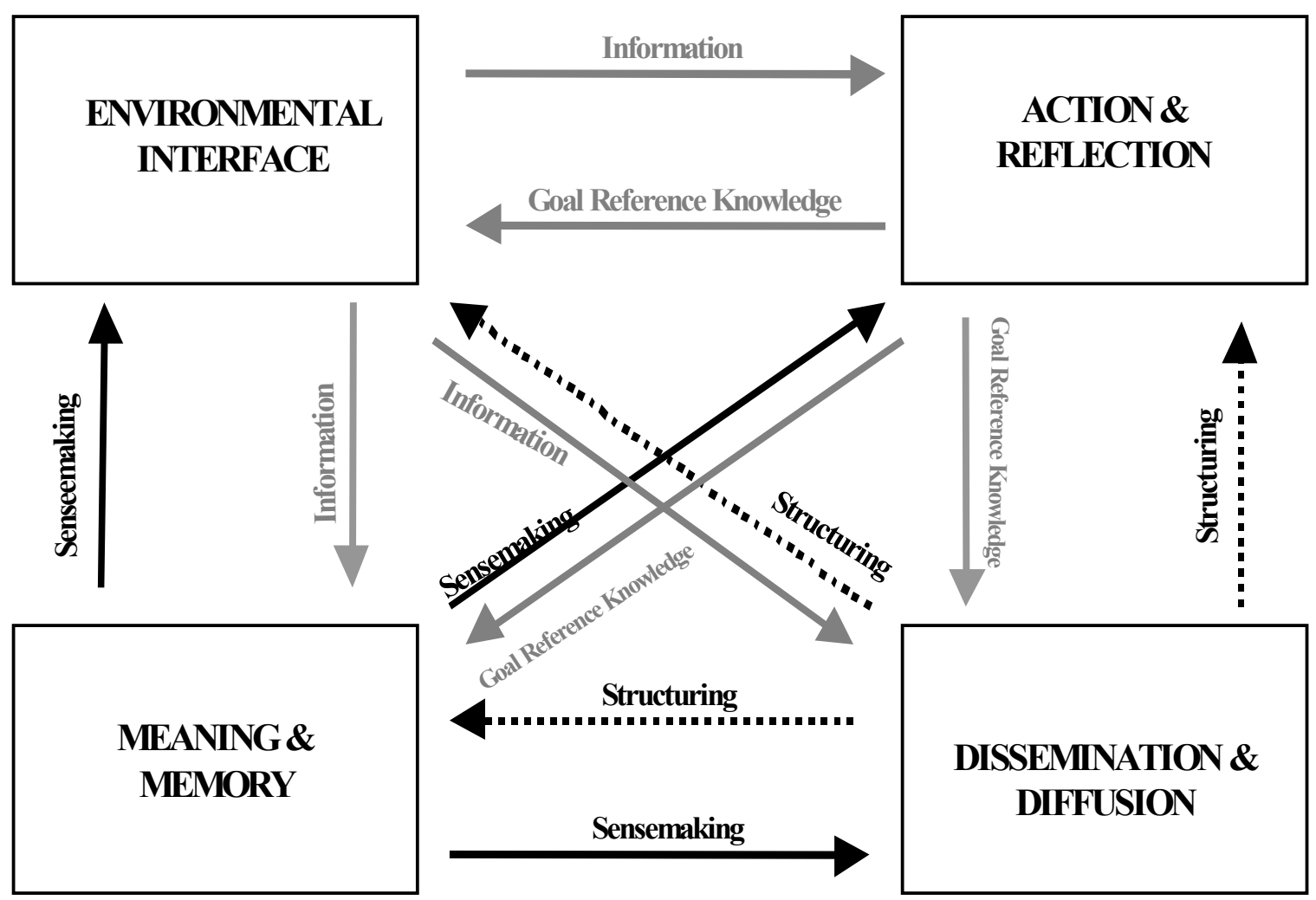

Figure 4: Media of interchange in Schwandt's learning subsystems 
This study focused specifically on the structuration and sense-making interchange media in a goal-oriented virtual project team. Structuring variables included in this study were information technology, roles, norms, leadership, rewards and recognition, and education and development. Sense-making variables are related to collective cognitive schema and behavioural actions of the team that are essential for organizational learning, and included values, language, scripts, and schema. Values represent an understanding of the operative culture. Language is a symbolic representation of assumptions. Scripts and schema are two terms for knowledge structures, which are the framework within which meaning is created. Schema represent shared meanings, mental models or frames of reference defined by Senge (1990:8) as "deeply ingrained assumptions, generalizations, or even pictures or images that influence how we understand the world and how we take action." Scripts are a special type of schema devoted specifically to the retention of context-specific knowledge about events and event sequences.

This study explored a number of structuring and sensemaking variables suggested in previous research using the Schwandt OLSM (Geigle, 1997; Gundlach, 1994; Hinds, 1995; Schwandt, 1994; 1999), with emphasis on collaborative technology as a structuring element that was expected to be critical to the functioning of a virtual project team.

\section{The study team}

The context for this study was one goal-oriented, virtual project team (VPT). Based on project requirements, the team selected had been formed with the intention of creating an optimum combination of skills and resources. Team members were physically, and often geographically, dispersed, not co-located. The team members could contribute to their team project at any time, from any place, and were comfortable and experienced using technology.

The site selected for this research was the KMT at BP. The principal participants in the virtual project team (the KMT) were 11 knowledge workers supporting the entire company of 55000 employees. They were located in Sunbury, London, and Scotland (UK), in addition to three part-time members located in Houston (Texas), Warrensville (Ohio), and Sunbury. The concept and core members of this knowledge management project came from the Virtual Teamworking Project, begun in 1995, to implement sophisticated technology to link employees and contractors who needed to share work, or expertise, at the same time from different places. This initial project created the foundation of the KMT's central tenets: to integrate people, processes, and technology.

The initial KMT was formed in 1997 to "accelerate the pace and benefits of BP's transformation to a learning organization, and maintain the momentum of existing knowledge efforts." Each KMT member joined the team with a commitment to participate in the long-term BP effort to innovate organizationally by developing systems, processes, teams, and individual employees in order to improve performance outcomes. The individuals on the team and in the knowledge management community provided a wealth of data about organizational learning and about the mechanisms by which organizational learning can, and did, influence learning and performance within BP.

A second group of participants, who provided insight for the study, were selected members of the KMC - a group of BP professionals (160 as of November 1998) interested in the field of knowledge management. All KMT members were by definition members of the KMC. The purpose of interviewing $\mathrm{KMC}$ members, beyond the team itself, was to validate the interpretations derived from the KMT member interviews, communications (email, telephone, etc.) and observations.

\section{Findings}

Since the focus of the study was on the learning subsystem, the performance subsystem terminates with evidence that the KMT completed its performance goals. The two subquestions related to structuring- and sense-making variables follow the learning construct. Figure 4 identifies themes and findings related to:

(a) structuring variables (IT, roles, norms, leadership, rewards and recognition and education and development); and

(b) sense-making variables (values, language, scripts and schema).

The themes and findings related to the collaborative technology construct are integrated into the learning subsystem as one of the IT structuring variables. This is indicated by the $[\mathrm{A}]$ symbol on Figure 4.

\section{Learning subsystem}

The researchers sought to understand elements that contextually define each of the structuring and sense-making variables as reported by the study's informants. After a short discussion of each variable from the perception of team members, the findings are summarized.

\section{Structuring - medium of exchange}

Figure 5 is a guide through subquestion 1 describing the six structuring variables and principal themes: IT, roles, norms, leadership, rewards and recognition, education and development. Detailed analysis of the coded interview transcripts, as well as observation at face-to-face meetings and informal conversations, revealed rich descriptions and these were summarized into 30 structuring principal descriptors

\section{Information technology}

Team members individually, and as a collective, actively use both the IT infrastructure and collaborative technology. This study divided the IT variable into two conceptual elements: IT infrastructure (composed of hardware, software, electronic networks, standards and support that allow employees to access applicable computer 
applications) and collaborative technology products that use the IT infrastructure to facilitate communication, coordination, collaboration and information sharing.

\section{IT Infrastructure:}

Team members recognized that a standard IT infrastructure is a prerequisite for virtual teams. At BP this requirement was met through a common operating environment (COE), a blueprint for technology that ensures that every BP computer meets minimum hardware and software standards. Negative aspects arise when the tool is too rigid or unavailable. BP has a strong commitment to developing a company-wide IT infrastructure as a strategic function and capability. The team members recognized that the IT infrastructure was a prerequisite for their team to operate virtually, and they expected connectivity and universal availability. A few team members complained about not being able to add non-standard software, or being behind in implementing the latest release of a particular software product, because of strict corporate guidelines about COE. The team also recognized that the organization-wide communication technology was rarely addressed directly, except when it did not work. Many team members indicated dependence on the existing IT infrastructure when they were asked directly, but did not volunteer the information. Among team members there was general awareness of possibilities for technology, as well as the limitations of the current environment. There was however optimism that, as technology capabilities evolved (e.g., more robust search engines), current limitations would diminish.

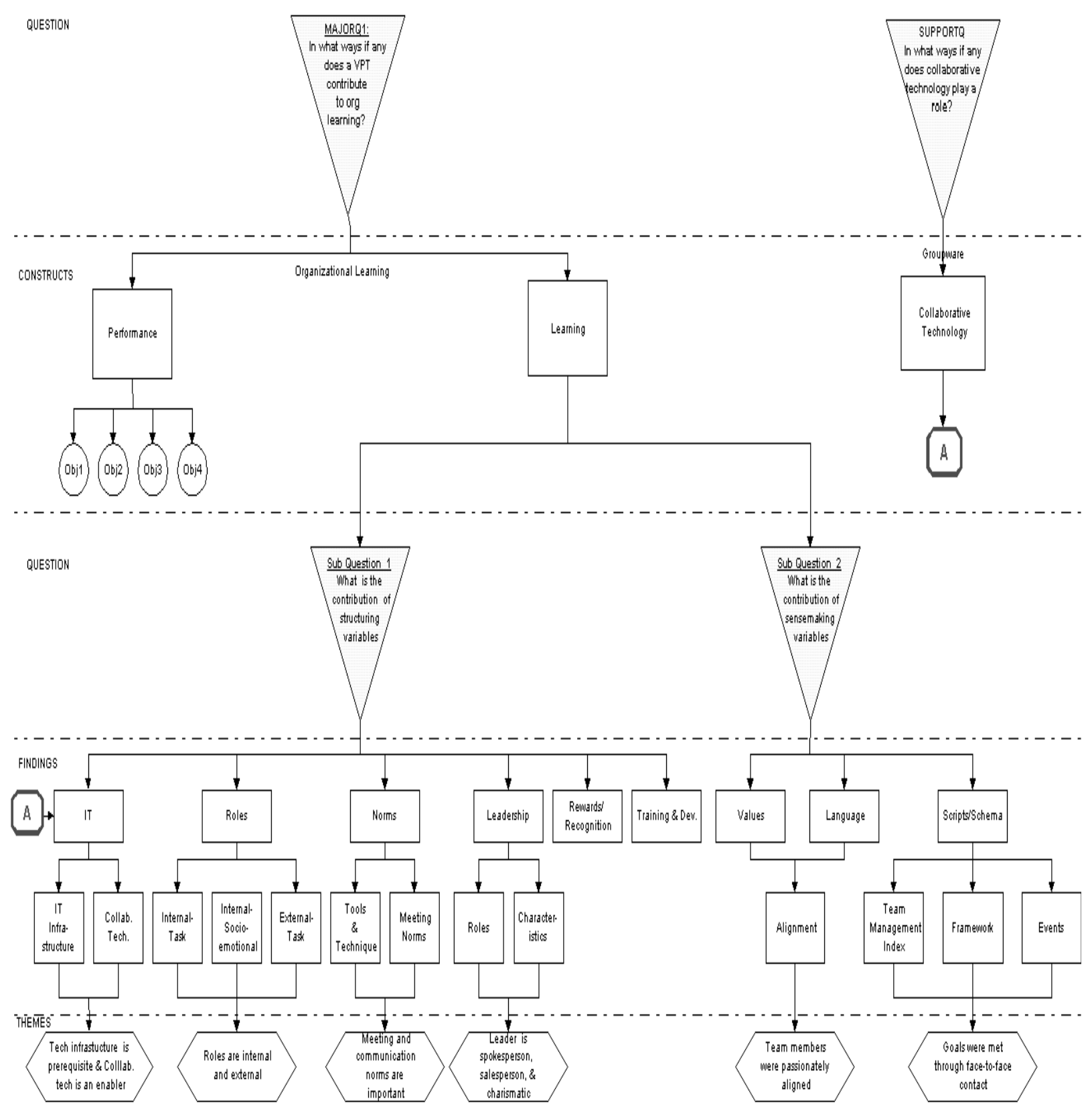

Figure 5: Flow of major research questions, findings and themes 
Collaborative technology:

The KMT members were active users of 'standard' (not customized) technologies (i.e., Microsoft Office, Microsoft Exchange). They did not differentiate between communication, coordination and collaboration functions for information sharing. Tools were used for different purposes (e.g., email, phone, $\mathrm{PC}$ videoconferencing) and were preferred by different team members. Most team members explicitly acknowledged that communication is complex, particularly in a virtual team.

\section{Roles}

Team members recognized that they assumed both formal and informal roles. In some cases the roles were defined and assigned, or assumed, by multiple team members. In a few cases the role was unique to a team member with secondary responsibility assigned to, or assumed by, another or other team member(s). The major factor differentiating roles was whether they were internal to the team (team process) or external (boundary spanning).

Within the KMT there were five role categories identified (Bales, 1950) that separated group activities into socioemotional and task-specific: (a) intragroup, internal to the $K M T$ - supporting the team's social/emotional issues; (b) intragroup, internal to the KMT - supporting the KMT's task issues; (c) cross boundary - internal to BP - supporting client business projects to meet their business objectives.

The KMT members explicitly described roles directly related to organizational learning, supporting the learning and performance subsystems for individuals, the KMT, business projects and the organization. In general the roles were reported to help workers share their learning and to demonstrate different approaches to sharing information. Each team member described himself and others on the team as playing multiple roles. The team members also valued outside perspectives and experts. Outsiders supported the KMT in every role category. Although the leader was the primary and positional leader, many people performed leadership functions based on the given context.

Discussion about individual and team roles generated more principal descriptors than any of the other structuring variables.

\section{Norms}

Norms are associated with procedures, tools, techniques and rules. Table 1 lists KMT norms, with specific techniques, tools, and procedures identified by category or type. For example findings related to norms were derived from conversations that described norms that the KMT established, as well as norms participants recommended as good, or best, practices for future knowledge management efforts. Communication and team meetings were the most significant procedural norms. The tools and techniques the team developed as components of the knowledge management toolkit were central to the team and BP.
Table 1 : KMT norms identified during interviews

\begin{tabular}{l|l}
\hline \multicolumn{1}{c|}{ Norm } & \multicolumn{1}{c}{ Type } \\
\hline Peer Assist & Technique-face-to-face activity \\
\hline After Action Review & Technique-face-to-face-activity \\
\hline Retrospect & $\begin{array}{l}\text { Technique-face-to-face or } \\
\text { electronic activity }\end{array}$ \\
\hline Knowledge Asset & $\begin{array}{l}\text { Technique-creating an electronic } \\
\text { history of a topic or activity }\end{array}$ \\
\hline Learning History & $\begin{array}{l}\text { Technique-obtaining a written } \\
\text { record of a project or event }\end{array}$ \\
\hline Virtual Teamworking & $\begin{array}{l}\text { Tool-hardware, software and } \\
\text { coaching process }\end{array}$ \\
\hline $\begin{array}{l}\text { Use of KMC discussion database } \\
\text { for general knowledge } \\
\text { management interchange }\end{array}$ & $\begin{array}{l}\text { Tool-software and facilitation } \\
\text { techniques }\end{array}$ \\
\hline Connect & Tool-software \\
\hline $\begin{array}{l}\text { Standard presentations e.g., for } \\
\text { engagement }\end{array}$ & Tool-electronic content \\
\hline Connect & Tool-software \\
\hline $\begin{array}{l}\text { Team meetings every other } \\
\text { Thursday }\end{array}$ & Procedure-agreement \\
\hline Meeting formats-agenda, notes, & Procedure-agreement \\
\hline $\begin{array}{l}\text { Quarterly team performance } \\
\text { review meeting with outside } \\
\text { facilitator-Away Days }\end{array}$ & Procedure-agreement \\
\hline $\begin{array}{l}\text { PC (VT) (or phone conference) } \\
\text { attendance at team meetings if } \\
\text { face-to-face not feasible }\end{array}$ & Rule-expectation \\
\hline
\end{tabular}

\section{Leadership}

Leadership, in four areas (Tissen, Andriessen \& Deprez, 2000), emerged as a significant descriptor in the KMT analysis: (1) the area of knowledge management in which they will be expected to sense and respond, combine and connect, and create and produce unstructured knowledge, (2) the area of team management in which they must direct and guide, coordinate and control, and participate and develop high potential in colleague team members, (3) they must involve themselves in talent management to detect and develop, and (4) they will have to become involved in self management and self development by applying refresh and refocus at regular intervals in their career (discussed further in the education and development section).

\section{Rewards and recognition}

Rewards and recognition from the perspective of structure (compensation and bonus policies and procedures) were not mentioned in the interviews. Many respondents touched on the subject as it applied to their sense of accomplishment and motivation. These comments are discussed in the sensemaking section on values.

\section{Education and development}

Professional development was expected (by the researchers) to be important for KMT members who were moving from scientific backgrounds to the relatively new field of knowledge management. This was not the case, since KMT members received no formal, or collective, training on knowledge management - except through presenting at, and attending, conferences. The only seminar KMT members attended introduced an instrument to evaluate individuals' 
preferred roles in a team. Personal development was also not something raised by KMT members. In addition, there was no mention of a training or development requirement in anyone's personal performance goals.

The team members were very aware of the need to develop and deliver knowledge management awareness education for BP business project clients, or potential clients. Several team members mentioned specific programs that were offered. However, they were not standardized to embed the tools and techniques that the KMT developed. In retrospect, all the team members stated that not developing a formal course was a mistake and limited the knowledge transfer of the team's work. Everyone agreed that a formal training program is critical for institutionalizing knowledge management. They were also aware that by not having the requirement to build a standard training program in the performance contract, it was not done. It remains an open task in the team objective to raise knowledge management awareness.

\section{Sense-making medium of exchange}

Figure 6 is a guide through the three sense-making variables: values, language, and scripts/schemas.

\section{Values}

Open business values (Morosini, 2000) are the degree to which a team's, or company's, key social actors share, enact and communicate to others' basic principles of behaviour which encourage learning, sharing of information and insights, and transparent communication. Values were evident and often expressed explicitly by KMT respondents. For example, the commitment on theme. In addition to explicit statements, many of the ussions and observations. What also became evident, from our research, was how the team's members and leaders embraced, acted and communicated those basic values - which appeared to be more important than the values themselves. In many respects, the strong passion for the new knowledge management discipline, and the will to make it succeed, drove the team's accomplishments.

Values that were expressed explicitly or implicitly by respondents related to rewards, learning, and the significance of time to accomplish change.

\section{Rewards and recognition}

Even though the importance of motivation is recognized, no integrated theoretical framework has thus far been developed - especially in the field of knowledge management. What is clear though, is that established motivational theories, such as Maslow and Herzberg successful for industrial bureaucracies, will not necessary work for the new generation of knowledge workers. In practice, many different approaches have been used to optimize motivation with varying degrees of success (Van Breukelen \& Van der Vlist, 1997).
In general, we believe that motivation (therefore learning and performance) is directly related to personal, organizational, and societal values, and motivation is therefore looking at why people do the things they do. It is about people's drives, wants, needs, values, goals, emotions, accomplishments and actions (Tissen et al., 2000). Individual motivation in the KMT was highest when the following circumstances and norms were met and valued:

- $\quad$ when a team member believed that what he or she was doing would lead to certain outcomes (performanceoutcome expectancy);

- when a team member felt that he or she was playing a meaningful role at the start of something significant to the organization (performance-outcome expectancy);

- $\quad$ when a team member believed that he or she would be recognized (with little or no financial rewards), both within the team and in greater BP, for the contribution they have made (internal recognition expectancy);

when a team member was made aware of articles, books and conferences citing the BP KMT as a worldclass leader in knowledge management (external recognition expectancy);

- when the team member believed that his or her own, personal learning was of value and could contribute to the KMT learning (individual-team learning expectancy);

- when a team member believed that his or her colleagues were committed to the goals and objectives of the KMT (team-performance expectancy);

- $\quad$ when a team member believed that the desired levels of learning and performance were possible, given the resources, competencies and skills he or she possessed (effort-performance expectancy and effort-learning expectancy);

when the team member believed that he or she was seen to be assisting and developing others (interpersonal-performance expectancy) ;

when a team member communicated his or her desire to sustain the team effort of the KMT, through agreeing to the equal distribution of performance bonuses (team sustainability expectancy);

- when a team member witnessed his or her colleagues choosing to continue to work in knowledge management, rather than return to their original disciplines (team sustainability expectancy); and

when a team member believed that he or she would be continuously learning something new - since knowledge management is a relatively underdeveloped discipline (personal-learning expectancy). 


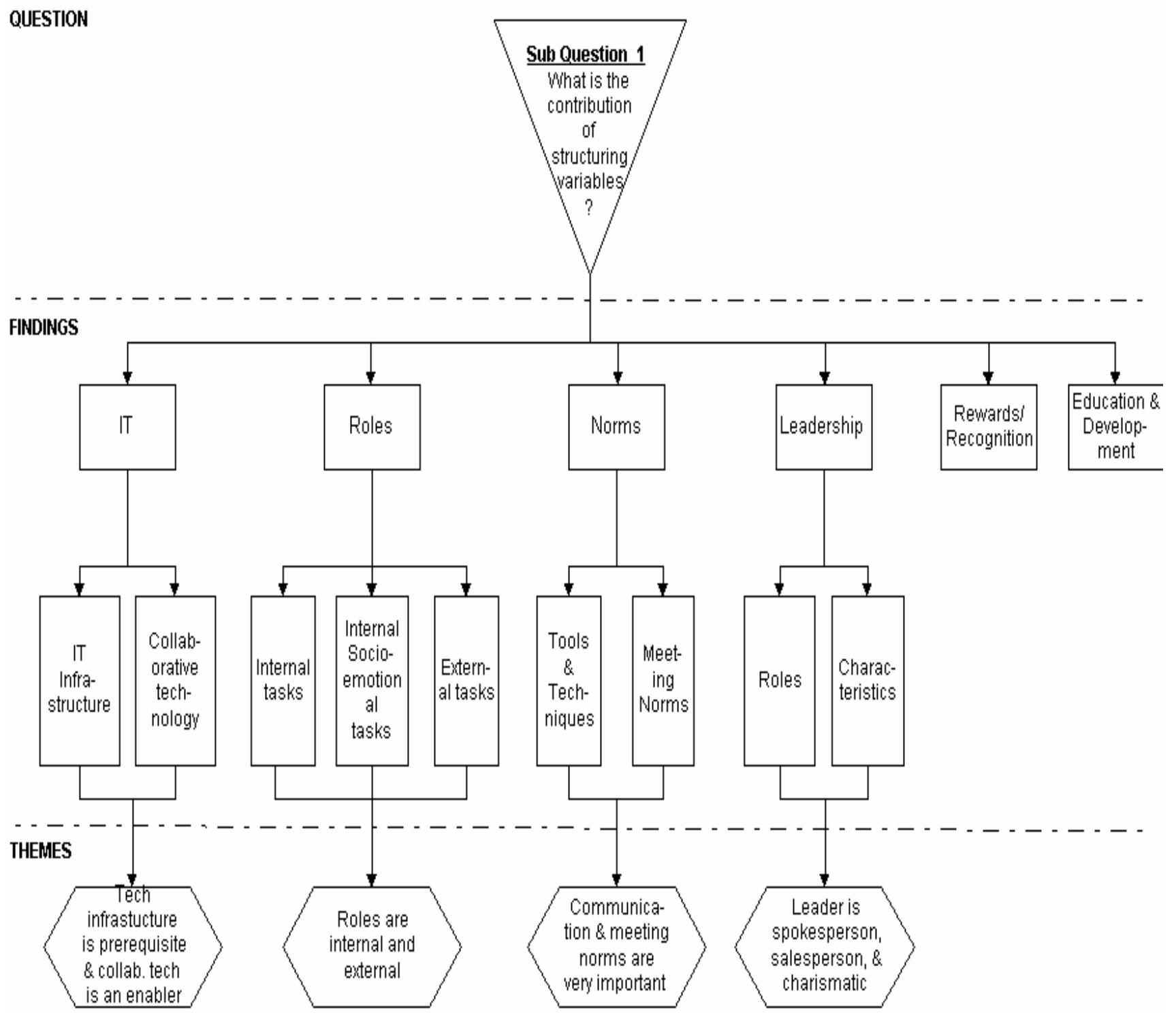

Figure 6: Subquestion 1- findings and themes

\section{Learning}

The three key areas of learning (social, cognitive and feedback) were spoken about by every team member as critical to personal, team and organizational goals. Many examples, showing the effective use of KMT tools to accomplish learning objectives, were reported.

The KMT exhibited time-based perseverance and focus on embedding knowledge management concepts and tools in the organization, and Stewart's (1997) 'virtuous cycle' became evident ('People learn to do things that become stories, that become documents, that go on a network, that people use to learn how to do things'). Team members reported individual successes, disappointments, and failures. Interviewees were well aware of the iterative learning that came from pilot projects and other diverse projects. Learning as a collective (team or BP as an organization) was important to all the team members, which led to the importance of sharing information to accomplish learning. All team members were all committed to both sharing and acquiring information. One member described it as 'openness'. Listening to team members, it was obvious that there is a genuine desire to share what they know. There was frustration when someone offered to share, and the offer was not taken up.

\section{Culture}

Several members mentioned that, outside the KMT, the prevailing BP organizational culture takes precedence over team norms. Most KMT members were long-term BP employees (17 years average) and aware of the history of the dominant engineering culture. Team members described the culture as one dominated by cowboys, analytics, and engineers - which obviously had implications with regard to, what Davenport and Prusak (1998:102) terms, the learning- and knowledge 'viscosity' (the richness or thickness of the knowledge transferred, and how much of it is actually absorbed and used within the organization) and 'velocity' (the speed with which knowledge is disseminated throughout, and moves through, an organization). The KMT members expressed joy in their ability to act differently within the KMT social network. 


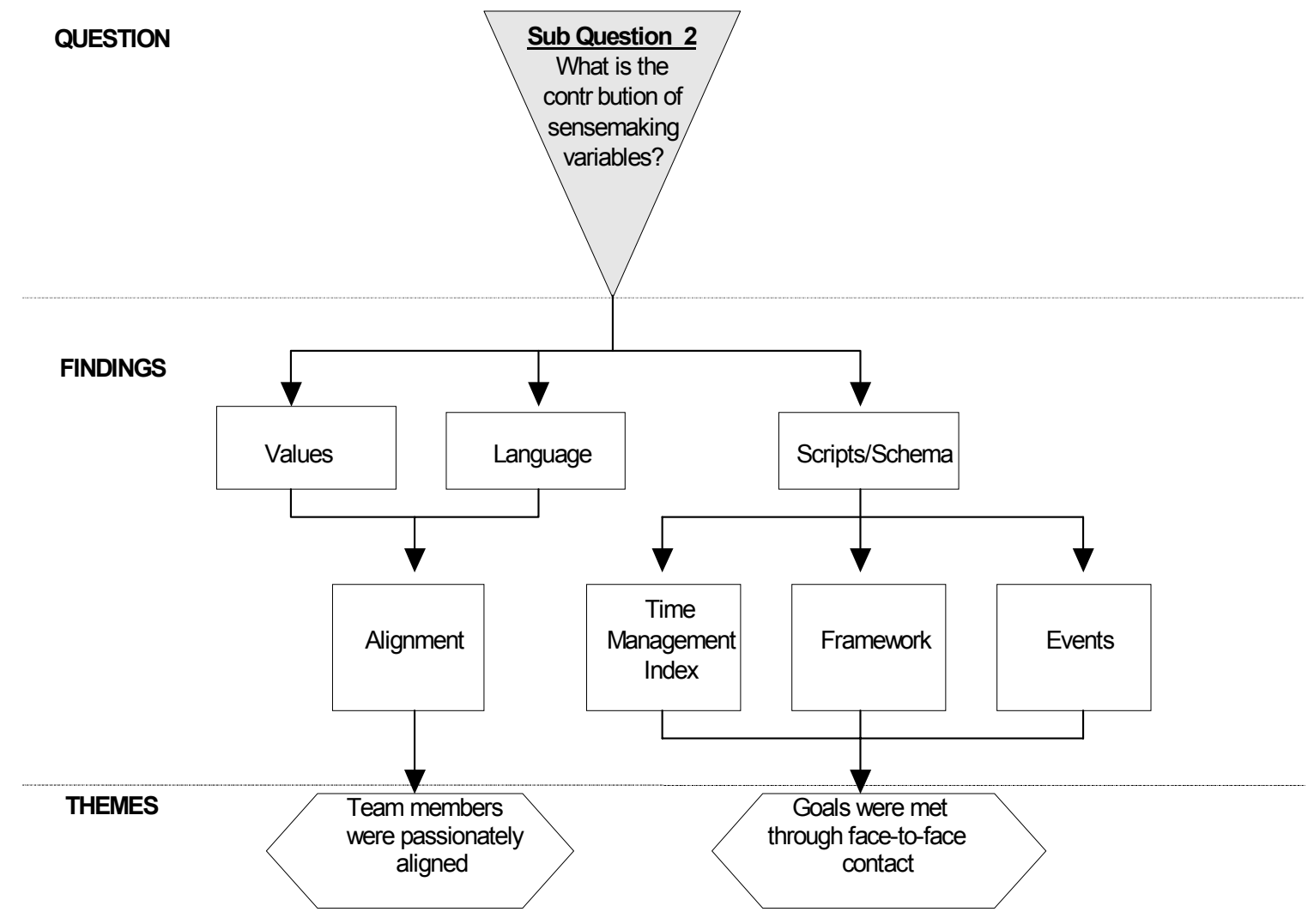

Figure 7: Subquestion 2 - findings and themes

Team members also recognized the BP culture as not oriented towards mandates, creating an imperative for the KMT to engage with people to voluntarily adopt processes, etc. Values and assumptions were consistent within the team, but in many cases the members were aware of the tension that resulted from the creative dualities arising from within themselves as individuals, and with the KMT and the BP culture, thereby creating a need for balance (what, we the researchers, term: bounded-identity tension).

\section{Language}

A major factor in the success of any virtual team project is the common, and shared, language of its members, which serves to build trust among them. Without it, individual team members will neither understand, nor trust, one another. The first component of trust is behaviour predictability - hence, the issue of time raised in a previous section. We usually use the word 'trust' to mean that we believe that people will act in a predictable, good and positive manner. We can just as well believe that people will act in a bad or negative manner. Trust is only the positive face of predictability: the negative face (shadow side) is just as important. Either way, we increase our ability to predict through communication and the establishment of language norms. Nonaka and Takeuchi's (1995) emphasis on 'redundancy' (overlapping areas of expertise) and Allen's (1977) discussion of 'cultural mismatch' as a barrier to technology transfer both recognize the importance of common ground. Hence, initially all that team members had on which to build trust was their commonality of expertise and experience (performance track record) within BP. Later, they would develop and appreciate a shared language, and trust then became a 'feeling'.

All KMT members, in our research, used the same language to describe the team's strategy and tactics. In many cases, the language was reflected in tools and techniques and were embedded in scripts. For example, every team member during the interviews stated the central concept of learning before, during, and after an event. It became doctrine for the team (almost evangelical). The language discussion does not address differences in country of origin, although those were obvious and a source of humour between the researchers and the team.

The awareness of the need to learn was included in the language used by team members during conversations. It is also noted that this language of knowledge management was not yet embedded in the general BP culture, which at times was an issue for team members. In BP's engineering culture, rationality and analytic language are norms. KMT members were aware of the shift in their use of language from analytic to language related to senses, relationships and feelings. The word 'passion' is used specifically and demonstrated in the words and actions of interviewees.

Team members were aware of language that did not match the mental models (world views) of engineers. Several team members recognized a few of their colleagues as evangelists. Faith was frequently mentioned as a characteristic of the team's work, as in the following statement: 
'There is an act of faith for knowledge management as opposed to building a platform and delivering a specific result ... The team is driven by a common belief in delivering something worthwhile.'

Over time the KMT evolved consistent people-oriented usage of some common terms (network, VT). The term 'network' was also often used by team members. Outsiders sometimes assumed that they were referring to a technology network. In this study, the technical network issues are addressed in the IT infrastructure section. The context for KMT members using the term 'network' is the formal networks within the BP organizational infrastructure, and at times communities of people who share interests (the learning network).

\section{Scripts and schemas}

The team was consistent in describing scripts and schemas that were central to their work. The scripts included an overall framework for the team's work, 0 a model that integrated people, process and technology functions, and an instrument with its associated model used to understand individuals' preferred roles within the team. These scripts were repeatedly used throughout the fieldwork, during interviews and observation. In addition to scripts, the team had many schemas related to their 'journey.' The team members were consistent in describing important events (episodic memory) during the KMT project - building, what we term, their story-memory.

One of the major accomplishments mentioned by all team members is the development of the knowledge management framework that guided the team's work - an intersecting circle model for people, process, and technology - the key components of the team's approach to organizational learning and basic to all KMT discussions and presentations. Several team members emphasized that the early knowledge management focus at BP, and most companies, has been technological, and more money has been spent on technology than on processes and people. The KMT, however, recognized the importance of people and process and worked at the intersection of the three components to accomplish learning before, during and after a project. During interviews, many informants referred to an individual in a specific role. For example, the internal team member who packages materials for distribution was described as a 'completer/finisher.' When the researcher probed for the meaning of these roles, members described a team role assessment instrument, the Team Management Index (TMI), which provided a foundation for the team's internal understanding of themselves and each other. Individual interviewees responded to the question about team effectiveness by describing specific events or episodic memory. This view was corroborated during the all day Retrospect on the $12^{\text {th }}$ February 1999 when the team used the map constructed as pre-work to trigger the discussion of the team's journey. The events most often mentioned in the interviews were the Milan Knowledge Exchange that formed the KMC and the Innovation Colloquia. These events were face-to-face, and a combination of face-to-face with webcasting respectively. At the face-to-face Retrospect, team process events were also discussed as critical-creating the engagement presentation, developing the knowledge management framework, quarterly review meetings, and reports to the knowledge management steering committee.

The Milan Knowledge Exchange (September 1997) was conceived and implemented as an event to break through other initiatives competing for change attention. One hundred people were brought together to share best practices in knowledge management. Some attended at the urging of KMT members, whilst others came because of the strategy fit and it was something people could relate to. The meeting was an opportunity for the KMT to reveal their plan, with the goal of obtaining input and ownership from attendees. One KMT member described the Milan Knowledge Exchange as 'the most successful event as [a] team'.

Another event orchestrated by the KMT in 1998, and a highlight in the team's collective memory, was the Innovation Colloquium. This was a face-to-face meeting attended by forty BP business unit executives as well as external innovation experts, a futurist, a senior officer from the U.S. Army and executives from innovative companies. A member of the KMT said, 'Since the topic was innovation, we wanted to use innovative methods of getting people to participate in the event.' Therefore, the KMT supported the colloquium (they did not initiate it). People who could not attend the event personally were encouraged to attend virtually. More than 1,700 of the 20,000 BP employees with Intranet access attended. Key deliverables were developed and major breakthroughs occurred in sametime communication, most often face-to-face. In addition to the major events described above, every team member raised the importance of team meetings for social reconnections, creating team plans, models, and presentations. Though everyone agreed that face-to-face was valuable many informants described very positive same-time different-place work sessions.

Part II will focus on the study's extensive findings.

\section{References}

Allen, T. 1977. Managing the flow of technology: Technology transfer and the dissemination of technological information within the $R$ and $D$ organization, Boston: MIT Press.

Bales, R. F. 1950. Interaction process analysis. Cambridge, MA: Wesley Press.

Botkin, D. J. 1999. Smart business: How knowledge can revolutionize your company. New York: The Free Press.

Casey, A. 1997. 'Collective memory in organizations'. In J. Walsh \& A. Huff (Eds.). Advances in strategic management. Greenwich CT: JAI Press, Inc., 14: 111-154.

Darr, E. D. \& Goodman, P. S. 2000. 'New research opportunities in computer-aided learning Systems.' In Cooper, C. \& Rousseau, D. (Eds.). Trends in organizational behaviour, West Sussex: John Wiley \& Sons, 7: 63-78. 
Davenport, T.H. \& Prusak, L. 1998. Working knowledge : How organizations manage what they know. Boston, MA: Harvard Business School Press.

DeSanctis, G. \& Poole, M. S. 1994. 'Capturing the complexity in advanced technology use: Adaptive structuration theory,' Organizational Science, 5:121-147.

Drucker, P. F. 1993. The effective executive. New York: Harper Business Press.

Duarte, D. L. \& Snyder, N. T. 1999. Mastering virtual teams: Strategies, tools, and techniques that succeed. San Francisco: Jossey-Bass.

Engelbart, D. 1992. 'Toward high-performance organizations: A strategic role for groupware.' In Coleman, D. (Ed.). Groupware 92 : Proceedings of the Groupware '92 Conference (1-4 August, San Jose, CA), San Mateo, California: Morgan Kaufmann Publishers.

Feldman, M. S. 1989. Order without design. Stanford CA: Stanford University Press.

Garvin, D. A. 1993. 'Building a learning organization,' Harvard Business Review, July-August: 81-91.

Geigle, S. 1997. 'Schemas and sensemaking during radical organizational change: A case study of reengineering in a federal agency'. Unpublished dissertation, The George Washington University, Washington, DC.

Gundlach, A. M. 1994, 'Sensemaking and organizational learning: The link between organizational meaning and the creation of knowledge'. Unpublished doctoral dissertation, The George Washington University, Washington, DC.

Hinds, R. C. 1995. 'Information technology and organizational learning: A case study of structuring in a military environment'. Unpublished qualitative study, The George Washington University, Washington DC.

Johnson, C. G. \& Gorman, M. D. 1999. 'Analyzing performance and learning in Organizations'. Paper presented at the Conference on Human and Organizational Studies, Washington, DC.

Johnson-Lenz, P. \& Johnson-Lenz, T. 1994. 'Groupware for a small planet'. In P. Lloyd, (Ed.). Groupware in the 21st Century: Computer supported cooperative working toward the millennium. Westport, CT: Praeger Press.

LeCompte, M. D., Preissle, J. \& Tesch., R. 1993. Ethnography and qualitative design in educational research. 2nd Edition. San Diego: Academic Press.

Lincoln, Y. \& Guba, E. 1985. Naturalistic inquiry. Beverly Hills, CA: Sage.

Lipnack, J. \& Stamps, J. 1997. Virtual teams: Reaching across space, time, and organizations with technology. New York: John Wiley \& Sons.
Lloyd, P. \& Boyle, P. 1998. Web-weaving. Oxford: Butterworth-Heinemann.

Martin, A. 1994. An organizational development primer. Los Catos, CA: Alexis Martin, Intersections Consulting Group.

Miles, M, \& Huberman, A. 1994. Qualitative data analysis, 2nd Edition. Thousand Oaks, CA: Sage Publications.

Morosini, P. 2000. 'Open company values: Transforming information into knowledge-based advantages.' In Marchand, D.A. (Ed.). Competing with information: A manager's guide to creating business value with information content. Chichester: John Wiley \& Sons Ltd. pp. 243-262.

Neilson, R. 1997. Collaborative technologies \& organizational learning. Hershey, PA: Idea Group Publishing.

Nonaka, I. \& Takeuchi, H. 1995. The knowledge-creating company. New York: Oxford University Press.

O’Hara-Devereaux, M. \& Johansen, R. 1994. Globalwork: Bridging distance, culture, and time. San Francisco: JosseyBass.

Olson, G. M. \& Olson, J. S. (in press). 'Research on computer supported cooperative work.' In Helander. M.E.A. (Ed.). Handbook of human computer interaction. Amsterdam: Elsevier.

Opper, S. \& Fersko-Weiss, H. 1992. Technology for teams: Enhancing productivity in networked organizatiosn. New York: Van Nostrand Reinhold.

Orlikowski, W. 1992. Learning from notes: Organizational issues in groupware implementation. Boston MA: MIT, (CISR WP No. 241).

Orlikowski, W. J. \& Yates, J. 1994. 'Genre repertoire: The structuring of communicative practices in organizations,' Administrative Science Quarterly, 39(4):541.

Parsons, T. 1951. A sociological approach to the theory of organizations: The social system. New York: The Free Press.

Parsons, T. 1968. The structure of social action. New York: The Free Press.

Popper, M. \& Lipshitz, R. 1998. 'Organizational learning mechanisms: A structural and cultural approach to organizational learning,' Journal of Applied Behavioral Science, 34: 161-179.

Patton, M. Q. 1990. Qualitative evaluation and research methods. 2nd Edition. Beverly Hills, CA: Sage Publications.

Prusak, L. 1997. Knowledge in organizations. Newton, MA: Butterworth-Heinemann. 
Rheingold, H. 1993. Virtual reality. New York: Simon \& Schuster.

Riggs, W. M., Bellinger, W. H. \& Krieger, D. B. 1996. 'The impact of groupware: Work process automation and organizational learning,' Technology Analysis \& Strategic Management, 8(3): 271-282.

Rocher, G. 1979. Talcott Parsons and American sociology. New York: Barnes and Noble.

Schrage, M. 1990. Shared minds: The new technologies of collaboration. New York: Random House.

Schrage, M. 1995. No more teams! Mastering the dynamics of creative collaboration. New York: Doubleday.

Schwandt, D. R. 1994. 'Organizational learning as a dynamic sociological construct: Theory and research' Paper presented at the International Systems Dynamics (ISD) Conference University of Scotland.

Schwandt, D. R. 1995. 'Learning as an organization: a journey into chaos.' In Chawla, S. \& Renesch, J. (Eds.). Learning organizations: Developing cultures for tomorrow's workplace. Portland: Productivity Press.

Schwandt, D.R. 1997. 'Integrating strategy and organizational learning: a theory of action perspective,' In J.P. Walsh \& A.S. Huff (Eds.). Advances in strategic management, London: JAI Press.

Schwandt, D. R. 1999. 'Linking organizational action patterns and collective cognition.' Paper presented at the European Institute for Advanced Studies in Management's Sixth Annual Workshop on Managerial and Organizational Cognition, University of Essex, Colchester, U.K.

Schwandt, D. R., Casey, A. \& Gorman, M. 1998. 'Dynamic role of collective memory in knowledge systems: A human action theory perspective.' Paper presented at the Academy of Management Midyear Conference on Organizational Learning: Moving from Theory to Research, Ashburn, VA, USA, 22-23 March..

Seidman, L.E. 1991. Interviewing as qualitative research: A guide for researchers in education and the social sciences. New York: New York Teachers College Press, Columbia University.

Senge, P. M. 1990. The fifth discipline: The art and practice of the learning organization. New York: Doubleday.

Sessa, V., Hansen, M., Prestridge, S. \& Kossler, M. 1999. Geographically dispersed teams, an annotated bibliography. Greensboro, NC: Center for Creative Leadership.

Stewart, T. 1997. Intellectual capital, the new wealth of organizations. New York: Doubleday/Currency.

Strauss, A. \& Corbin, J. 1990. Basics of qualitative research. Newbury Park, CA: Sage Publications.
Tissen, R., Andriessen, D. \& Deprez, F.L. 2000. The knowledge dividend: Creating high-performance companies through value-based knowledge management. London: Financial Times-Prentice Hall.

Townsend, A. M., DeMarie, S. M. \& Hendrickson, A. R. 1998. 'Virtual teams: Technology and the workplace of the future,' Academy of Management Executive, 12(3):17.

Van Breukelen, W. \& Van der Vlist, R. 1997. 'Motivation, work and organizational psychology (Motivatie en Arbeidsen Organisatiepsychologie),' De Psycholoog, February: 70.

Weick, K. E. 1995. Sensemaking in organizations. Thousand Oaks, CA: Sage Publications.

Yin, R. K. 1989. Case study research: Design and methods. $1^{\text {st }}$ Edition. Newbury Park, CA: Sage Publications.

Yin, R. K. 1994. Case study research: Design and methods, Vol. 5. Newbury Park, CA: Sage Publications. 